\title{
Effect of Heel Raise Exercise with NMES on Peroneus Longus Muscle Strength and Postural Control Ability in Subjects with Functional Ankle Instability: Randomized Controlled Trial
}

\author{
Joon Ho Seo', Jeon-Hyeong Lee², Mi Young Lee ${ }^{3}$ \\ 'Yeungnam University Medical Center, Rehabilitation Center, Daegu, Republic of Korea; ${ }^{2}$ Department of Physical Therapy, Daegu Health College, \\ Daegu, Republic of Korea; ${ }^{3}$ Department of Physical Therapy, College of Biomedical Science, Daegu Haany University, Daegu, Republic of Korea
}

Purpose: This study examined the effects of heel raise exercises combined with neuromuscular electrical stimulation (NMES) on the muscle strength and postural control ability of subjects with functional ankle instability (FAl).

Methods: Twenty-two subjects with FAl participated in this study. They were assigned randomly to two groups: 11 each in the NMES and the sham-NMES groups. Heel raise exercise was applied, and NMES electrodes were attached to the peroneus longus muscles. The NMES group applied NMES during the heel raise exercise. NMES was applied for 20 minutes during the heel raise exercise. The heel raise exercise was performed four times a week for five weeks. The muscle strength and balance error scoring system (BESS) were measured before and after the intervention.

Results: A comparison of before and after the intervention within the groups revealed improved muscle strength in the NMES and Sham-NMES groups, but the BESS was improved under all conditions only in the NMES group. The Sham-NMES group showed no improvement in the unstable support surface. Furthermore, when comparing the amount of change before and after the intervention between the groups, there were significant differences in the total score and unstable support in the BESS and muscle strength.

Conclusion: NMES had a positive effect on the functional activities of the functional ankle instability subjects, such as balancing on an unstable support surface during postural control and increasing muscle strength.

Keywords: Heel raise exercise, Neuromuscular electrical stimulation, Muscle strength, Postural control

\section{서 론}

발목은 신체의 자세 정렬 시 기초를 이루는 관절이며, 신체 활동 시 관절 움직임과 체중지지 및 이동 시 안정성을 제공한다. ${ }^{1-3}$ 발목 관절 은 스포츠 활동 또는 일상생활에서 손상이 호발하는 부위이며 특히 가쪽 발목 염좌는 보행이나 점프에서 착지하는 동안 발 뒤쪽의 초기 접촉 직후에 가쪽 돌림된 다리에 대해 발 뒤쪽의 과도한 뒤침으로 인 해 빈번히 발생한다.46 발목 염좌를 경험하게 되면 신경조직과 근힘 줄 조직의 손상으로 인하여 신경근 조절 능력이 저하되고, 발목 관절 구조물의 느슨함을 초래하게 되어 발목 염좌가 빈번하게 재발될 수 있다. ${ }^{4}$ 가쪽 발목 염좌 후 적절한 치료 및 관리를 하지 않아 발생하는 반복적인 발목 염좌는 발목 관절의 만성적인 불안정성을 초래하게 되며 이는 만성 불안정성 발목 상태를 유발하게 된다..$^{8}$ 기능적 발목 불

Received Jan 12, 2021 Revised Feb 02, 2021

Accepted Feb 03, 2021

Corresponding author Mi-Young Lee

E-mail mykawai@hanmail.net 안정성(functional ankle instability)이란 가쪽 발목 염좌를 경험한 환자 들 중 $40 \%$ 에서 나타나며 발목이 '꺾이는 주관적 느낌을 받는 것이다.9

기능적 발목 불안정성을 가진 환자는 잦은 가쪽 발목 염좌를 경험 함으로써 발목관절의 고유수용성감각의 저하, 발목 관절을 지지하 는 근육들의 반응 시간의 지연, 정적 및 동적 균형, 자세조절 능력의 결핍, 발목 가쪽번짐근의 근약화와 같은 임상 증상이 나타난다.,10-15 특 히, Bellew 등른 기능적 발목 불안정성이 긴종아리근의 약화와 감 각-운동의 기능저하와 관련이 있으며, 긴종아리근은 가쪽 발목을 지 지하는 중요한 근힘줄 조직과 동시에 발목 가쪽의 동적 안정성 증가 를 위한 운동 프로그램 시 중점을 두는 근육이라 하였다. 또한 이러 한 기능적 발목 불안정성을 가진 대상자에게 선행연구에서는 자세 조절 능력 개선을 위한 테이핑 요법, 균형 능력 개선을 위한 체중지지 균형훈련과 단일 균형 훈련, 고유수용성감각 훈련, 협응 훈련 등의 중

Copylight (C)2021 The Korean Society of Physical Therapy

This is an Open Access article distribute under the terms of the Creative Commons Attribution Non-commercial License (https:// creativecommons.org/license/by-nc/4.o.) which permits unrestricted non-commercial use, distribution, and reproduction in any medium, provided the original work is properly cited. 
재들을 적용하였다.16-18 특히, 발 뒤꿈치 들기 운동은 발목 관절 발바 닥굽힘근의 강화를 위한 일반적인 운동으로, 비교적 간단하며 발 뒤 꿈치 들기 운동 시 자세조절을 요하여 기능적 활동의 수행능력을 개 선시킬수 있다.19

신경근 전기자극은 근력 증가, 수의적 운동 조절의 개성, 관절가동 범위 증가, 기능적 움직임 회복 등 다양한 목적을 위해 지속적으로 사용되어 왔다. ${ }^{20,21}$ 효과에 대한 선행 연구로, 뇌졸중 환자들을 대상 으로 자발적, 수동적 신경근 전기자극을 이용한 손 쥐기(grasp) 운동 을 적용한 결과 자발적 신경근 전기자극 손 쥐기 운동을 한 집단이 수동적 신경근 전기자극 손 쥐기 운동 집단보다 중재 직후 수행 속도 가 $10 \%$ 이상 증가하였다.2기능적 발목 불안정성 대상자에서 신경근 전기자극을 이용한 넙다리네갈래근의 최대 수의적 등척성 수축 운 동이 넙다리네갈래근의 근력 증가로 인하여 통증의 감소 및 기능 개 선에 긍정적인 영향을 미쳤으며, 보존적 물리치료를 받은 집단보다 신경근 전기자극을 병행한 보존적 물리치료를 받은 집단이 기능적 인 면에서 유의한 개선을 보여주었다. ${ }^{23} 12$ 주간 노인의 발바닥 굽힘근 에 신경근 전기자극을 적용한 결과 발바닥 굽힘근의 근력이 증가되 었으며, 나아가 앞쪽 방향의 안정성 한계의 증가에도 유의한 영향을 미친 것으로 보고되었다. ${ }^{24}$ 또한 만성폐쇄성폐질환을 가진 환자들에 게 복합호흡운동을 병행한 신경근 전기자극 치료를 넙다리네갈래근 에 적용하였을 때 1 초간 노력성 날숨량과 6 분 보행검사 시 유의한 개 선을 나타냈다.25

위와 같은 신경근 전기자극을 적용한 다양한 중재가 선행되었지 만 기능적 발목 불안정성을 가진 대상자에게 신경근 전기자극을 적 용한 중재에 대한 연구는 미비한 실정이다. 따라서 본 연구는 기능적 발목 불안정성을 가진 대상자에서 신경근 전기자극을 병행한 발 뒤 꿈치 들기 운동이 근력과 자세조절 능력에 미치는 영향을 알아보기 위해 실시하였다.

\section{연구 방법}

\section{1. 연구대상}

본 연구는 대상자 선정기준에 적합한 성인 22명이 참가하였으며 대 상자는 신경근 전기자극군(NMES) 11 명과 위약 전기자극군(ShamNMES) 11 명으로 무작위 배정되었다(Table 1). 대상자 선정에 대한 기 준은 다음과 같다. 1) Cumberland Functional Ankle Instability Tool Questionnaire 24점 이하로 기능적 발목 불안정성 발목을 가진 자, 2) 한 번이라도 발목 염좌를 경험한 자, 3) 하지와 척추에 선천적 기형이 나 질병이 없는 자, 4) 심장박동조율기가 없는 자, 5) 발목과 관련된 의 학적 및 물리치료적 중재를 받지 않은 자. 연구는 헬싱키 선언의 윤리 원칙에 따라 수행하였으며, 대구한의대학교 부속 대구한방병원 임상
시험심사위원회의 승인을 받았다(DHUMC-D19014-PRO-02). 또한 대상자들에게 연구에 대한 충분한 설명을 제공한 뒤 동의서를 얻어 진행하였다.

\section{2. 실험방법}

1) 측정도구 및 방법

(1) 근력

발목의 안쪽과 가쪽 번짐 근력은 Commander Muscle Tester (JTECH Medical, USA)를 사용하여 측정하였다. 발목 가쪽 번짐 근력 측정을 위해 대상자는 발목을 중립으로 위치한 후 앉아서 시행하였다. 치료 사는 한 손으로 대상자의 복사뼈 바로 위를 잡아 발목을 안정화시키 고, 발의 5 번째 발허리뼈머리와 가쪽 가장자리에 콘솔을 위치시켜 저 항을 안쪽번짐과 발등굽힘 방향으로 저항을 가하였다. 또한 발목 안 쪽 번짐 근력 측정을 위해 대상자는 발목을 약간 발바닥 굽힘 상태로 위치한 후 앉아서 시행하였다. 치료사는 한 손은 마찬가지로 복사벼 위 발목관절을 고정하고 저항은 발허리뼈 머리 부위에서 안쪽 부분 에 콘솔을 위치시키고 가쪽번짐과 약간의 발등굽힘 방향으로 저항 을 가하였다. ${ }^{26}$ 기능적 발목 불안정성을 가진 발에 3 회씩 측정하여 평 균값을 사용하였다.

\section{(2) 자세조절 능력}

자세 조절 능력 측정을 위해 Balance Error Scoring System (BESS)을 사 용하였다. BESS는 안정적과 불안정적 표면에서 세 가지 발 위치(Double-leg, Single-leg, Tandem stances)에서 각각 2번씩 총 6번 시도하였다. 각 조건에서 대상자들에게 눈을 감으라 지시한 후 손을 엉덩뼈능선 에 올리게 한 후 움직임 없이 20초 동안 유지하라고 지시하였다. 만약 각 자세를 유지하는 동안 대상자들이 균형을 잃는다면 가능한 빨리 검사 자세로 되돌아 가라고 지시하였다. BESS의 수행시 오류는 엉덩 뼈능선에서 손을 들어 올릴 때, 눈을 뜰 때, 깡총 뛰거나 발부리에 걸 리거나 넘어질 때, 엉덩이를 $30^{\circ}$ 이상 굽히거나 벌릴 때, 앞발 또는 발 뒤꿈치를 들어 올릴 때, 5 초 이상 검사자세를 벗어나 있을 때 오류를 체크하여 총점을 산출하였다. ${ }^{27} \mathrm{BESS}$ 의 총점은 안정적, 불안정한 지 지면 2조건 각각 30 점이며, 점수가 낮을수록 균형 능력이 뛰어나다고 해석할수있다.

\section{3. 중재 방법}

\section{1) 신경근전기자극}

신경근전기자극은 Walking Man II EMG FES 3000 (Cybermedic, Korea)을 사용하였다. 긴종아리근의 근수축 유발을 위해 긴종아리근의 근힘살 부위에 전극을 부착하였다. 자극 시간은 20 분, 자극파형은 단 상파 맥동전류, 주파수 $30 \mathrm{~Hz}$, 펄스폭 $200 \mu \mathrm{s}$, 상승시간 1 second, 지속 
시간 4 second, 하강시간 1 second, 휴지시간 2 second로 설정하였다. 자 극 강도는 대상자가 불편함을 느끼지 않는 정도에서 최대 가쪽 번짐 이 나타나도록 적용하였다.

\section{2) 발 뒤꿈치 들기 운동}

발 뒤꿈치 들기 운동 시 발바닥 굽힘뿐만 아니라 가쪽 번짐을 동반하 여 긴종아리근의 수축을 유도하기 위해 긴종아리근이 정지하는 1 번 발허리뼈 머리(1st metatarsal head)와 5 번째 발허리뼈 머리(5th metatarsal head) 아래 각각 동전을 놓은 후 발 뒤꿈치 들기 운동 시 1번 발 허리뼈 머리로 동전을 누르고 5 번째 발허리뼈 머리는 동전을 누르지 않도록 하였다. 신경근 전기자극군의 경우 전기자극이 통전되는 4 초 간 발 뒤꿈치를 완전히 들어 올려 끝자세를 4 초간 유지하도록 지시하 였으며, 필요 시 최소한의 지지를 제공하였다.

\section{3. 실험 절차}

신경근 전기자극군은 신경근 전기자극과 함께 발 뒤꿈치 들기 운동 을 실시하였고, 위약 전기자극군은 전극을 부착하였지만 신경근 전 기자극을 적용하지 않고 발 뒤꿈치 들기 운동만을 실시하였다. 두 군 모두 발 뒤꿈치 들기 운동을 15 회를 1 세트로 설정하여 총 5 세트를 실 시하였으며 5 주간 주 4 회 실시하였다.

\section{4. 자료 분석}

분석방법연구 결과 분석을 위해 SPSS ver 25.0 for Window를 사용하

Table 1. General Characteristics of the Subjects

\begin{tabular}{lcccc}
\hline & NMES & Sham-NMES & $t$ & $p$ \\
\hline Sex (M/F) & $11(4 / 7)$ & $11(4 / 7)$ & 0 & 1 \\
Age (yr) & $20.6 \pm 1.7$ & $21.9 \pm 2.4$ & -1.427 & 0.169 \\
Height (cm) & $165.2 \pm 5.8$ & $168.9 \pm 9.4$ & -1.122 & 0.275 \\
Weight (kg) & $64.7 \pm 11.4$ & $63.9 \pm 13.6$ & 0.153 & 0.880 \\
CAIT (score) & $18.2 \pm 3.4$ & $20.4 \pm 3.2$ & -1.556 & 0.135 \\
\hline
\end{tabular}

NMES: Neuromuscular electrical stimulation with heel raise exercise, CAIT: Cumberland ankle instability tool.
였으며, 정규성 검정을 위해 Shapiro-Wilk 검정을 사용하였으며, 집단 간 대상자들의 일반적인 특성에 대한 동질성 검증은 독립 t-검정(independent t-test)을 사용하였다. 집단 내 중재에 따른 효과를 알아보 기 위하여 대응표본 t-검정(paired t-test)를 사용하였고, 중재에 따른 변화량의 그룹 간 차이를 알아보기 위하여 독립 t-검정(independent $\mathrm{t}$ test)을 실시하였다. 통계적 유의 수준은 $\alpha=0.05$ 로 하였다.

\section{결 과}

\section{1. 집단 내 변화 비교}

신경근 전기자극군의 경우 중재 전후에 따른 근력과 자세조절 능력 (안정 및 불안정한 지지면과 총점)에서 유의한 차이가 나타났다 $(\mathrm{p}<$ 0.05). 한편, 위약 전기자극군의 경우 근력과 일부 자세조절 능력(안정 된 지지면과 총점)에서 유의한 차이가 나타났다 $(\mathrm{p}<0.05)($ Table 2).

\section{2. 집단 간 변화량 비교}

중재 전과 후의 변화량에 대한 신경근 전기자극군과 위약 전기자극 군 비교 시 근력과 자세조절 능력(안정 및 불안정한 지지면과 총점)에 서 유의한 차이가 나타났다 $(\mathrm{p}<0.05)($ Table 3$)$.

Table 3. Comparison of the pre-intervention and post-intervention changes between the two groups

\begin{tabular}{lcccc}
\hline & NMES & Sham-NMES & $\mathrm{t}$ & $\mathrm{p}$ \\
\hline Strength (E/l \%) & $44.54 \pm 24.62$ & $26.02 \pm 15.42$ & 2.114 & $0.047^{*}$ \\
BESS (score) & & & & \\
$\quad$ Firm & $-3.36 \pm 1.63$ & $-1.91 \pm 1.04$ & -2.493 & $0.022^{*}$ \\
Foam & $-5.18 \pm 1.60$ & $-1.45 \pm 3.42$ & -3.276 & $0.005^{*}$ \\
Total & $-8.55 \pm 1.81$ & $-3.36 \pm 3.96$ & -3.950 & $0.001^{*}$ \\
\hline
\end{tabular}

NMES: Neuromuscular electrical stimulation with heel raise exercise, E/l: Ratio of evertor strength per inverter strength, BESS: Balance error scoring system, Firm: Firm surface, Foam: Foam surface.

${ }^{*} p<0.05,{ }^{+} p<0.001$.

Table 2. Comparison of pre and post-intervention in the NMES and Sham-NMES.

\begin{tabular}{|c|c|c|c|c|c|c|c|c|}
\hline & \multicolumn{4}{|c|}{ NMES } & \multicolumn{4}{|c|}{ Sham-NMES } \\
\hline & pre & post & $\mathrm{t}$ & $\mathrm{p}$ & pre & post & $\mathrm{t}$ & $p$ \\
\hline Strength (E/I\%) & $53.44 \pm 13.04$ & $97.98 \pm 16.38$ & 6.001 & $<0.001^{+}$ & $60.92 \pm 15.22$ & $86.94 \pm 9.64$ & 5.599 & $<0.001^{+}$ \\
\hline \multicolumn{9}{|l|}{ BESS (score) } \\
\hline Firm & $4.73 \pm 2.28$ & $1.36 \pm 1.29$ & 6.847 & $<0.001^{+}$ & $4.73 \pm 1.85$ & $2.82 \pm 1.54$ & 6.062 & $<0.001^{+}$ \\
\hline Foam & $7.82 \pm 1.17$ & $2.64 \pm 0.81$ & 10.734 & $<0.001^{+}$ & $6.27 \pm 3.26$ & $4.82 \pm 0.98$ & 1.412 & 0.188 \\
\hline Total & $12.55 \pm 2.38$ & $4.00 \pm 1.55$ & 15.667 & $<0.001^{+}$ & $11.00 \pm 4.58$ & $7.64 \pm 2.5$ & 2.820 & $0.018^{*}$ \\
\hline
\end{tabular}

NMES: Neuromuscular electrical stimulation with heel raise exercise, E/l: Ratio of evertor strength per inverter strength, BESS: Balance error scoring system, Firm: Firm surface, Foam: Foam surface.

${ }^{*} p<0.05,{ }^{+} p<0.001$. 


\section{고 찰}

본 연구는 기능적 발목 불안정성을 가진 대상자에서 신경근 전기자 극을 병행한 발 뒤꿈치 들기 운동이 근력과 자세조절 능력 영향을 알 아보기 위해 실시하였다. 연구 결과 신경근 전기자극군은 근력과 자 세조절 능력(안정 및 불안정 지지면과 총점)에서 중재 전후 유의한차 이를 보였다. 반면 위약 전기자극군의 경우 근력, 일부의 자세조절 능 력(안정된 지지면과 총점)에서 유의한 차이가 나타났지만 불안정한 지지면에서는 유의한 차이를 나타나지 않았다. 또한 중재 전과 후의 변화량에 대한 집단 간 비교에서 근력, 자세조절 능력(안정 및 불안정 한 지지면과 총점)에서 유의한 차이가 나타났고, 신경근 전기자극군 의 변화량이 더 컸다.

기능적 발목 불안정성을 가진 대상자들의 경우 지속적 발목 염좌 로 인하여 긴종아리근 약화, 수축 시간 지연 그리고 고유수용성감각 저하와 같은 문제점들이 나타난다. ${ }^{10-12}$ Bowker 등 ${ }^{30}$ 은 기능적 발목 불 안정성을 가진 대상자들의 종아리근에서 근수축 반응시간이 유의 하게 낮게 나타남을 보고하였다. 또한 $\mathrm{Kim}^{15}$ 은 발목 염좌를 경험한 발레 선수 32 명에게서 긴종아리근의 근활성도가 낮게 나타나는 것 을 보고하였다. Lee 등28은 기능적 발목 불안정성을 가진 대상자들의 근력을 정상인과 비교한 결과 등속성 근력이 $60 \% \mathrm{sec}$ 에서 발바닥 및 발등굽힘근, 안쪽 및 가쪽번짐근의 근력이 유의하게 감소되었다고 보고하였다.

위의 선행 연구들로 미루어 보았을 때, 가쪽 발목 염좌 후 발목 관 절의 기능 회복을 위해 시행하는 운동은 근력 및 근조절기능 향상에 초점을 두고 있다. $18,31,32 \mathrm{Bellew}$ 등 ${ }^{12}$ 은 긴종아리근의 생역학적 역할을 고려하여 긴종아리근의 근활성화를 더욱 유도할 수 있는 발 뒤꿈치 들기 운동을 고안하였는데, 운동 방법은 발 뒤꿈치 들기 운동 시 긴 종아리근의 수축을 유도하기 위해 긴종아리근이 정지하는 1 번 발허 리뼈 머리와 5번째 발허리뼈 머리 아래 각각 동전을 놓은 후 발 뒤꿈 치 들기 운동 시 1 번 발허리빼 머리로 동전을 누르고 5 번째 발허리뼈 머리는 동전을 누르지 않도록 하였다. 이 방법은 근전도 상에서 일반 적인 발 뒤꿈치 들기 운동보다 긴종아리근의 높은 근활성도를 확인 할 수 있었다. 본 연구에서는 Bellew 등리 지 제시한 발 뒤꿈치 들기 운 동을 적용하였으며, 그 결과 두 집단 모두에서 근력이 향상되었음을 확인하였다.

근력을 증가시킬 수 있는 방법 중 하나로 운동 단위의 동원 수를 증 가시키는 것이 있다. 수의적 근수축의 경우 신경지배율이 낮은 운동 단위부터 동원되어 점차 더 큰 힘을 필요로 할 때 신경지배율이 높은 운동 단위로 점진적으로 동원된다. 이를 헤네만의 크기 원리 (Henneman's size principle)라 정의한다. 수의적인 근수축의 경우 피로 도에 저항이 강한 느린 운동단위에서부터 동원되어 빠른 운동단위
로 순서적으로 동원이 이루어 지는 것에 반해, 신경근 전기자극을 통 한 근수축의 경우 근섬유 동원에 따른 뚜렷한 순서가 없이 근육을 활성화시킨다. 즉, 비선택적이고 동시간적인 운동 단위의 동원 패턴 이 나타난다. ${ }^{33,34}$ 또한, Gregory와 Bickel ${ }^{34}$ 은 전기자극 시 크기 원리의 역설(reversal of size principle)을 제안하였는데, 이는 큰 운동 단위의 축삭은 작은 운동 단위의 축삭보다 전류에 대하여 낮은 저항성을 가 지고 있으며 활동 전위에 대한 빠른 전도율을 통해 이와 같은 결과가 나타났다고 보고하였다. 위와 같은 이유로 신경근 전기자극을 병행 하여 운동을 할 경우, 수의적 운동만 수행한 경우보다 신경근 전기자 극으로 인해 운동 단위의 활성화 수를 동시적으로 증가시킴으로써 효율적인 근력의 증가를 기대할 수 있을 것으로 생각된다.

신경근 전기자극의 효과에 대한 선행 연구를 살펴보면, Lee 등 35 은 2-30대 정상 남녀에게 넙다리네갈래근에 수의적 등척성 운동 및 신 경근 전기자극을 적용하여 주 3 회, 4 주간 적용한 결과 4 주 후부터 근 력의 유의한 증가를 확인할 수 있었다. 또한, Veldman 등 36 은 신경근 전기자극을 이용하여 잠재적인 근지구력의 강화를 도모할 수 있다 고 보고하였다. Park 등근 앞십자인대 재건술 환자에게 신경근 전기 자극을 적용한 집단과 경피신경자극을 적용한 집단을 비교하였을 때 무릎 굽힘 및 폄 근력에서 신경근 전기자극을 적용한 집단에서만 유의한 증가가 나타났음을 보고하였다. 또한 Park과 Youn ${ }^{38}$ 은 뇌성마 비 아동 20명을 대상으로 신경근 전기자극을 병행한 승마운동을 하 였을 때 일반적인 물리치료를 받은 집단보다 왼쪽 및 오른쪽 등쪽 척 추근의 활성도가 유의하게 증가되었음을 보고하였으며, 실험군에서 대단위운동기능평가의 서기영역에 유의한 증가가 나타났음을 보고 하였다. 위의 선행 연구 결과들과 마찬가지로 본 연구의 결과에서도 유사한 결과를 확인할 수 있었는데, 본 연구에서 적용한 신경근 전기 자극이 발 뒤꿈치 들기 운동 시 긴종아리근의 신경지배율이 높은 운 동 단위의 동원을 더욱 유도하여 시너지 효과로 인해 위약 전기자극 군보다 유의한 증가를 나타낸 것으로 생각된다.

한편, Lee 등28은 기능적 발목 불안정성을 가진 대상자에서 정적 및 동적 균형 능력이 정상인과 비교하여 저하되어 있음을 보고하였다. 유사한 결과로 Docherty 등 27 은 기능적 발목 불안정성을 가진 대상자 들에게 자세조절 능력 검사시 한 발 들기 조건에서 안정 및 불안정한 지지면에서 정상인보다 더 많은 오류를 범하였으며 자세조절 능력의 결핍을 보고하였다. 기능적 발목 불안정성에 의해 나타나는 균형 및 자세조절 능력의 저하를 해결하기 위한 중재의 효과를 확인한 선행 연구를 살펴보면, Youssef 등17은 만성 발목 불안정성 여성을 대상으 로 주 3 회, 총 4 주간의 체중지지 균형 훈련, 단일 균형 훈련을 각각 적 용한 후 Biodex 균형 시스템을 사용하여 불안정한 지지면에서 환측 하지의 균형을 측정하였는데, 두 집단 모두 불안정한 지지면에서 환 측 하지의 균형에 증가가 나타났음을 보고하였다. Shin 등 29 은 기능적 
발목 불안정성을 가진 젊은 여성 11 명에게 발목 강화 운동(스쿼트, 발 뒤꿈치 들기 운동, 점프)를 3 주간 적용한 결과 발목 관절에서 발바닥 굽힘근과 발등굽힘근의 근력, 동적 및 정적 균형 능력의 개선을 보고 하였다. 본 연구에서 적용한 발 뒤꿈치 들기 운동 동안 신경근 전기자 극이 긴종아리근의 단독적인 수축을 더욱 유도하여 발목 관절의 안 정성 증가로 자세조절 능력 특히, 불안정한 지지면에서 자세조절 능 력의 오류가 감소한 것으로 생각된다.

본 연구에서는 기능적 발목 불안정성을 가진 대상자들에게 신경 근 전기자극을 병행한 발 뒤꿈치 들기 운동을 적용함으로써 대상자 들의 근력과 자세조절 능력이 향상되며 집단 간 비교 시에도 근력, 안 정 및 불안정한 지지면에서의 자세조절 능력이 위약 전기자극군에 비하여 개선되었음을 확인할 수 있었다. 이는 치료적 중재 또는 근력 강화 운동 프로토콜 적용 시 신경근 전기자극을 병행할 경우 근력 증 가는 물론 더욱 기능적이고 도전적인 과제 수행 시에도 긍정적인 영 향을 미칠 수 있을 것으로 생각된다. 임상적으로 본 연구는 기능적 발 목 불안정성을 가진 대상자들의 기능 회복을 위해 적용할 수 있는 치 료 프로토콜의 제안과 효과에 대한 근거를 제시한 것에 의미가 있을 것이다. 본 연구에서의 제한점은 일상생활에 문제가 없는 젊고, 경미 한 증상을 호소하는 기능적 발목 불안정성을 가진 대상자들을 상대 로 중재를 적용한 것이다. 앞으로의 연구에서는 노인 혹은 중등도의 기능적 발목 불안정성을 가진 대상자에서의 중재의 효과를 확인할 필요가 있을 것으로 생각된다.

\section{REFERENCES}

1. Starkey C, Ryan JL. Evaluation of orthopedic and athletic injuries. Philadelphia, FA Davis Company. 2015:237-45.

2. Kim HS. The Effect of the plantar pressure on dynamic balance by fatigue of leg in the subjects with functional ankle instability. J Digital Contents Society. 2016;16(1):734-42.

3. Yang DJ, Park SK, Um YH. Impact of virtual reality based neuromuscular postural control fusion training on balance ability and jump performance of soccer players with functional ankle instability. J Digit Converg. 2016;14(11):357-67.

4. Hertel J. Functional anatomy, pathomechanics, and pathophysiology of lateral ankle instability. J Athl Train. 2002;37(4):364-75.

5. Hertel J. Functional instability following lateral ankle sprain. Sports Med. 2000;29(5):361-71.

6. Kaminski TW, Hartsell HD. Factors contributing to chronic ankle instability: a strength perspective. J Athl Train. 2002;37(4):394-405.

7. Hubbard TJ, Kramer LC, Denegar CR et al. Contributing factors to chronic ankle instability. Foot Ankle Int. 2007;28(3):343-54.

8. Park SH. Effects of neuromuscular training on muscle activity and balance ability in badmintons club members with chronic ankle instability. J Kor Phys Ther. 2016;28(4):243-8.

9. Freeman MAR, Dean MRE, Hanham IWF. The etiology and prevention of functional instability of the foot. J Bone Joint Surg. 1965;47(4):678-85.

10. Tropp H. Commentary: functional ankle instability revisited. J Athl Train. 2002;37(4):512-5.

11. Olmsted LC, Carcia CR, Hertel J et al. Efficacy of the star excursion balance tests in detecting reach deficits in subjects with chronic ankle instability. J Athl Train. 2002;37(4):501-6.

12. Bellew JW, Frilot CF, Busch SC et al. Facilitating activation of the peroneus longus: electromyographic analysis of exercises consistent with biomechanical function. J Strength Cond Res. 2010;24(2):442-6.

13. Kim CY, Choi JD. Comparison between ankle proprioception measurements and postural sway test for evaluating ankle instability in subjects with functional ankle instability. J Back Musculoskelet Rehabil. 2016; 29(1):97-107.

14. Kwon YW. Static postural stability in chronic ankle instability, an ankle sprain and healthy ankles. Int J Sports Med. 2018;39(8):625-9.

15. Kim HJ. Ankle sprain affects lower leg muscle activation on vertical landing half point, and gait in female ballet students. J Kor Phys Ther. 2019;31(2):129-33.

16. Jackson K, Simon JE, Docherty CL. Extended use of kinesiology tape and balance in participants with chronic ankle instability. J Athl Train. 2016;51(1):16-21.

17. Youssef NM, Abdelmohsen AM, Ashour AA et al. Effect of different balance training programs on postural control in chronic ankle instability: a randominzed controlled trial. Acta Bioeng Biomech. 2018;20(2): 159-69.

18. Park YH, Kim HJ. Conservative management and postoperative rehabilitation of chronic lateral ankle instability. J Korean Foot Ankle Soc. 2019;23(1):6-11.

19. Flanagan SP, Song JE, Wang MY et al. Biomechanics of the heel-raise exercise. J Aging Phys Act. 2005;13(2):160-71.

20. Daly JJ, Ruff RL. Construction of efficacious gait and upper limb functional interventions based on brain plasticity evidence and model-based measures for stroke patients. Sci World J. 2007;10(3):187-91.

21. Denegar CR, Saliba E, Saliba S. Therapeutic modalities for musculoskeletal injuries. 4th ed. IL, Human Kinetics, 2015:171.

22. Santos M, Zahner LH, Mckiernan BJ et al. Neuromuscular electrical stimulation improves severe hand dysfunction for individuals with chronic stroke: a pilot study. J Neurol Phys Ther. 2006;30(4):175-83.

23. Hasan S. Quadriceps femoris strength training: effect of neuromuscular electrical stimulation vs isometric exercise in osteoarthritis of knee. Indian J Physiother Occup Ther. 2015;9(3):129.

24. Langeard A, Bigot L, Loggia G et al. Plantar flexor strength training with home-based neuromuscular electrical stimulation improves limits of postural stability in older adults. J Phys Act Health. 2020;17(6):657-61.

25. Kang JI, Park JS, Jeong DK. The effect of neuromuscular electrical stimulation on pulmonary function, gait ability, quality of life in patients with chronic obstructive pulmonary disease. J Kor Phys Ther. 2018;30(4): 129-34.

26. Hislop HJ, Avers D, Brown M. Daniels \& Worthingham's muscle testing. 9th ed. St Louis, Elsevier, 2014:257-67.

27. Docherty CL, McLeod TC, Shultz SJ. Postural Control deficits in participants with functional ankle instability as measured by the balance error scoring system. Clin J Sports Med. 2006;16(3):203-8.

28. Lee SA, Kim AR, Yoo KT et al. Evaluation of muscle activity and foot 
pressure during gait, and isokinetic strength and balance in persons with functional ankle instability. J Korean Soc Phys Med. 2018;13(3):27-37.

29. Shin YJ, Yoon TL. The short term effects of ankle strengthening emphasis with jumping on strength, mechanical properties, and balance with and without wearing high heel in ankle instability. J Kor Phys Ther. 2019; 31(4):176-83.

30. Bowker S, Terada M, Thomas AC et al. Neural excitability and joint laxity in chronic ankle instability, coper, and control groups. J Athl Train. 2016;51(4):336-43.

31. Uchida MC, Nishida MM, Sampaio RA et al. Thera-band elastic band tension: reference values for physical activity. J Phys Ther Sci. 2016;28 (4):1266-71.

32. Revak A, Diers K, Kernozak TW et al. Achilles tendon loading during heel-raising and-lowering exercise. J Athl Train. 2017;52(2):89-96.

33. Jubeau M, Gondin J, Martin A et al. Random motor unit activation by electrostimulation. Int J Sports Med. 2007;28(11):901-4.
34. Gregory CM, Bickel CS. Recruitment patterns in human skeletal muscle during electrical stimulation. Phys Ther. 2005;85(4):358-64.

35. Lee SC, Chae JR, Kim HJ. The effect of neuromuscular electrical stimulation and isometric exercise on the strength of the quadriceps femoris muscle. J Korean Soc Living Environ Sys. 2009;16(3):239-45.

36. Veldman MP, Gondin J, Place N et al. Effects of neuromuscular electrical stimulation training on endurance performance. Front Physiol. 2016; 7:544.

37. Park SJ, Lee JH, Lee DJ. The effects of electrical stimulation method on muscle strength, pain, range of motion, fear avoidance-belief in patients with anterior cruciate ligament reconstruction. JKAIS. 2017;18(6):53846.

38. Park SJ, Youn PS. Effects of NMES and horseback riding using a robotic device on the trunk muscle activity and gross motor function in children with spastic diplegia. J Kor Phys Ther. 2018;30(4):123-8. 